\title{
PRAKTIK MANAJEMEN PUBLIK DI PUSAT PENELITIAN DAN PENGEMBANGAN TEKNOLOGI MINYAK DAN GAS BUMI “LEMIGAS" DALAM PERSPEKTIF KEWIRAUSAHAAN ORGANISASI
}

\author{
Rukmono Hariwibowo \\ Student of Public Administration and Policy at University of Indonesia, Email: rukmonoh@ gmail.com \\ Martini Huseini \\ Student of Public Administration and Policy at University of Indonesia, Email: rukmonoh@ gmail.com
}

\begin{abstract}
Abstrak
Praktek pemerintahan wirausaha adalah isu yang populer di banyak negara. Di Indonesia, Pusat Penelitian dan Pengembangan untuk Teknologi Minyak dan Gas Bumi "LEMIGAS" adalah salah satu agen publik yang telah menerapkan praktik kewirausahaan pemerintah. Sejak akhir 2009, LEMIGAS telah ditetapkan sebagai pemerintah wirausaha dalam memberikan layanan teknologi minyak dan gas bumi. Ini dapat meningkatkan pendanaan organisasi melalui skema ini. Namun demikian LEMIGAS bukanlah lembaga yang mencari keuntungan semata karena peraturan pemerintah yang ketat. Penelitian ini merupakan metode kualitatif dengan menggunakan analisis kekuatan dan tantangan, data berasal dari sumber primer dan sekunder. Temuan penelitian adalah bahwa LEMIGAS memiliki kekuatan untuk mengimplementasikan praktik kewirausahaan pemerintah, tetapi juga menghadapi tantangan hukum pemerintah dan status organisasi.
\end{abstract}

Kata Kunci: Praktik, Kewirausahaan Pemerintah, Indonesia, LEMIGAS

\begin{abstract}
The practice of entrepreneurial governance is a popular issue in many countries. In Indonesia, the Research and Development Center for Oil and Gas Technology "LEMIGAS" is one of the public agencies that has implemented government entrepreneurial practices. Since the end of 2009, LEMIGAS has been established as an entrepreneurial government in providing oil and gas technology services. This can increase organizational funding through this scheme. However LEMIGAS is not a profit-seeking institution due to strict government regulations. This research is a qualitative method using strength and challenge analysis, the data comes from primary and secondary sources. The research findings are that LEMIGAS has the power to implement government entrepreneurial practices, but also faces legal challenges in government and organizational status.
\end{abstract}

Keywords: Keywords: Practice, Government Entrepreneurship, Indonesia, LEMIGAS

\section{PENDAHULUAN}

Untuk pemerintah, organisasi kewirausahaan telah menghadirkan kepercayaan dasar sebagai organisasi independen (Leathard, 2005). Dalam kondisi yang berlaku, organisasi publik sangat hirarkis terstruktur untuk memudahkan koordinasi satu sama lain dalam skala besar administratif untuk mencapai tujuan organisasi, itu disebut oleh Weber sebagai birokrasi (Slattery in Finlay dan Sandal, 2009). Di Indonesia, birokrasi pada lembaga publik tumpang tindih dengan hukum yang kaku yang mengelakkan beberapa praktik skema pendanaan, perilaku staf, produktivitas output, dan rencana masa depan. Tantangannya adalah bagaimana manajemen publik yang dicirikan dan diidentifikasi sebagai organisasi birokrasi dapat menjadi organisasi yang adaptif dan responsif terhadap pasar.

Sejak 2005, Pemerintah Indonesia memiliki Undang-Undang Pemerintahan No. 23/2005 tentang Badan Layanan Umum (BLU). Ini berfokus pada organisasi publik yang berkaitan dengan pelanggan di pasar untuk mengurangi ketergantungan yang tinggi dari anggaran pemerintah. Peraturan ini membuka peluang bagi organisasi publik untuk menjadi mandiri dalam mengelola keuangan publik termasuk bagaimana mereka menciptakan pendapatan baru dan bagaimana mereka membelanjakan anggaran. Oleh karena itu, konsep kegiatan kewirausahaan untuk organisasi publik diperbolehkan asalkan mereka menjalankan entitas bisnis mereka dalam kerangka hukum Republik Indonesia. 
Salah satu contoh sukses kegiatan wirausaha adalah Pusat Penelitian dan Pengembangan Teknologi Migas (LEMIGAS). Lembaga publik ini adalah unit penelitian dan pengembangan $(R \& D)$ di bawah Kementerian Energi dan Sumber Daya Mineral (Kementerian-ESDM). LEMIGAS telah menjalankan aktivitas kewirausahaan sejak 2009. Meskipun tampaknya kurang bergantung pada anggaran pemerintah, LEMIGAS menghadapi tantangan terkait dengan undang-undang pemerintah dan status pemerintahan wirausaha dan organisasi publik.

\section{Latar Belakang Konsep Manajemen Publik}

Manajemen publik terkait dengan hubungan struktural, kontraktual, dan konvensional antara politisi dan pemimpin birokrasi. Kinerja birokrasi lebih dipengaruhi oleh politisi terpilih daripada administrator birokrasi terkemuka. Politisi yang kuat adalah tantangan, sehingga norma atau tradisi khusus diciptakan untuk menjaga netralitas pegawai negeri dari intervensi politik. Ini berkaitan dengan apa yang dapat dilakukan pegawai negeri dan berperilaku dalam tekanan politik (Stewart, 2009). Studi ini mendefinisikan bahwa manajemen publik mirip dengan karakteristik birokrasi dimana semua kegiatan secara ketat didorong oleh aturan pemerintah dan garis hirarki.

\section{Kewirausahaan Organisasi}

Aktivitas wirausaha benar-benar terkait dengan wirausaha, ia didefinisikan memiliki grand design dari hasil yang diinginkan. Selain itu, pengusaha lebih bersedia menghabiskan waktu dan energi dalam melobi para politisi, dan juga mendorong proyek mereka untuk menjadi lebih maju (Zahariadis, 2007). Dalam konteks kewirausahaan dalam organisasi publik, ada manajer berfungsi sebagai pemimpin transformasional yang berusaha untuk mengubah budaya organisasi. Mereka mampu mewujudkan visi organisasi menjadi kenyataan. Penting untuk dicatat, visi kewirausahaan tidak terbatas pada pemimpin puncak. Setiap manajer di tingkat organisasi, memiliki kemampuan untuk merencanakan dan menilai situasi di masa depan. Bagi mereka yang tidak bisa atau tidak memiliki kemampuan untuk mewujudkan visi atau mengubah rencana masa depan, dapat dikatakan bahwa mereka tidak kompeten. Efeknya, organisasi tidak berubah dan kemudian akan mati pada akhirnya (Shafritz et al. 2013).
Semangat pemerintah wirausaha dibunyikan di banyak negara berkembang termasuk di Indonesia. Oleh pemerintah kewirausahaan, lembaga publik berubah dari manajemen ilmiah yang diciptakan oleh Taylor menjadi manajemen publik yang berorientasi pelanggan (Shafritz et al. 2013). Dalam konteks kegiatan kewirausahaan, individu atau masyarakat menggunakan properti mereka untuk meningkatkan sumber daya keuangan untuk kegiatan kewirausahaan atau untuk memperluas produktivitas perusahaan yang ada (de Ferranti, 2009). Artinya, organisasi publik harus di luar kebiasaan, aktif dan kreatif untuk mencari sumber pendapatan baru, fleksibel dalam mengelola pendanaan publik, dan lebih tanggap terhadap pasar yang ada.

Dalam penelitian ini, aktivitas kewirausahaan atau Badan Layanan Umum (BLU) didefinisikan sebagai upaya organisasi publik untuk menjadi adaptif dan responsif di pasar melalui ide-ide inovatif, skema keuangan baru, dan model organisasi yang diterapkan untuk menjaga keberlanjutan organisasi.

\section{METODOLOGI PENELITIAN}

Penelitian didekati dengan metode kualitatif. Data berasal dari sumber primer dan sekunder yang dilakukan dari awal Desember 2017 hingga awal Januari 2018. Informan kunci adalah dua staf yang bekerja di LEMIGAS di Kementerian ESDM dan keterlibatan peneliti diri sebagai informan yang disengaja. Untuk menyelesaikan penelitian ini, data sekunder seperti jurnal ilmiah, buku, prosiding, tindakan, dan dokumen relevan lainnya digunakan. Penelitian ini menggunakan analisis kekuatan, kelemahan, peluang, dan ancaman (SWOT) yang berfokus pada dua elemen utama yaitu kekuatan dan ancaman (kemudian kita sebut dengan tantangan). Jasiulewicz-Kaczmarek (2016) menyatakan bahwa kekuatan dan ancaman adalah arah strategis dari jenis SWOT terkait dengan bagaimana memanfaatkan kekuatan utama organisasi untuk menangani dan mengurangi ancaman (tantangan) yang muncul di lingkungan eksternal.

\section{HASIL DAN PEMBAHASAN \\ Profil Pusat Penelitian dan Pengembangan Teknologi Minyak dan Gas Bumi "LEMIGAS" \\ Pusat Penelitian dan Pengembangan}

Teknologi Minyak dan Gas Bumi atau PPPTMGB "LEMIGAS" didirikan pada 11 Juni 1965. Ini adalah bagian dari Badan Litbang Kementerian Energi dan 
Sumber Daya Mineral (Balitbang ESDMKementerian ESDM). LEMIGAS adalah satu satunya unit penelitian dan pengembangan yang fokus dalam teknologi minyak dan gas bumi di Indonesia. Fungsi utama adalah tiga bidang yaitu: kemampuan penelitian, kemampuan laboratorium, dan repositori pengetahuan. Selain menyiapkan rekomendasi kebijakan di sektor minyak dan gas bumi, LEMIGAS diminta untuk menyediakan ahli minyak dan gas bumi untuk mengambil alih para ahli dari perusahaan minyak dan gas asing di Indonesia.

Di Indonesia, LEMIGAS memiliki kompetitor swasta dalam layanan laboratorium minyak dan gas bumi seperti perusahaan schlumberger, uni lab, dll. Untuk mempertahankan organisasi dan bersaing dengan kompetitor lain, LEMIGAS "dipaksa" untuk mencari penghasilan tambahan baru dan mengeluarkan anggaran secara tepat. Pada tanggal 28 Desember 2009, LEMIGAS mulai bertransformasi bentuk organisasi berwirausaha yaitu menjadi Badan Layanan Umum (BLU) agar tidak bergantung pada anggaran pemerintah dengan mencari sumber pendapatan baru melalui kerja sama dengan banyak perusahaan/ lembaga swasta dan negara. Hal ini berdasarkan Keputusan Menteri Keuangan Nomor 513/KMK.05/2009 dan Peraturan Menteri Energi dan Sumber Daya Mineral Nomor 24 Tahun 2014. Hal yang terkait dengan BLU terdapat dalam Peraturan Pemerintah Nomor 23 Tahun 2005 yang diperkuat oleh Peraturan Pemerintah Nomor 74 Tahun 2012 untuk selanjutnya telah dipraktikkan oleh PPPTMGB "LEMIGAS" hingga saat ini lebih dikenal dengan jargon BLU LEMIGAS.

Kemandirian anggaran menjadi salah satu tujuan BLU LEMIGAS, ini terlihat pada tren anggaran yang diberikan oleh pemerintah (APBN $\mathrm{RM}$ ) semakin menurun dan pendapatan (APBN PNBP) menjadi meningkat dari tahun ke tahun. Pada tahun anggaran 2016 - 2018 tren anggaran RM berturut - turut semakin menurun sebesar: Rp. 132 miliar (2016); Rp. 68 miliar (2017); dan Rp. 32 miliar (2018). Pendapatan BLU LEMIGAS pada tahun tersebut semakin meningkat dengan capaian realisasi sebesar: Rp. 64 miliar (2016); Rp. 75 miliar (2017); dan Rp. 85 miliar (2018).

Capaian tersebut menunjukkan praktik dari suatu kewirausahaan organisasi BLU LEMIGAS dalam bersaing dengan industri migas di dalam maupun di luar negeri. Namun demikian BLU LEMIGAS harus tetap dan terus menjalin hubungan baik dengan stakeholder (pelanggan) dengan cara kerja sama karena para pelangganlah yang telah berkontribusi sedikit banyak kepada pendapatan BLU LEMIGAS.

Pada tahun 2016 BLU LEMIGAS telah mempunyai 483 pelanggan yang terdiri dari kontraktor gabungan swasta, perusahaan minyak dan gas milik swasta dan negara, anak perusahaan minyak dan gas, lembaga publik/ pemerintah, dan perorangan. BLU LEMIGAS menyediakan layanan khusus untuk teknologi minyak dan gas kepada Kontraktor Kontrak Kerja Sama (KKKS) yaitu: Akademi Migas Balongan - Indonesia; Universitas Indonesia; Universitas Inha; Australian Volunteer International; PERTAMINA; Direktorat Jenderal Minyak dan Gas - Bumi Kementerian Energi dan Sumber Daya Mineral; Universitas Pembangunan Nasional Veteran Yogyakarta Perusahaan Minyak dan Gas Negara Indonesia/ PGN, dan masih banyak lagi).

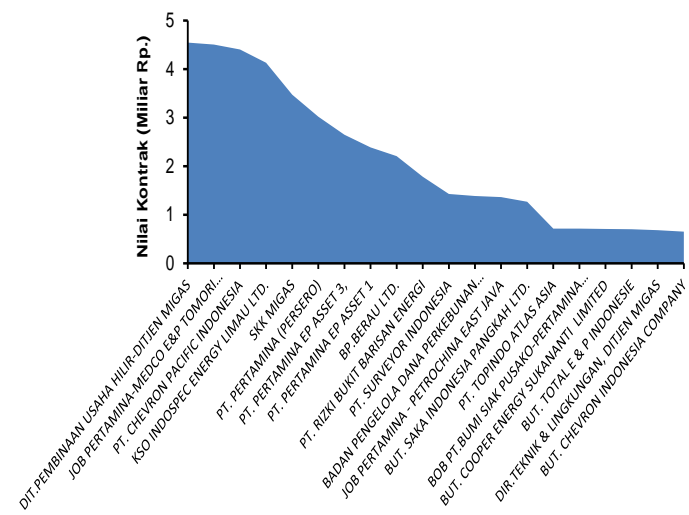

Gambar 1. Kontribusi 20 pelanggan terbesar terhadap layanan Jasa Teknologi BLU LEMIGAS Tahun 2016 (Rp. miliar) Sumber: LEMIGAS (2017)

\section{Kemampuan BLU LEMIGAS}

Untuk mengoptimalkan pemerintah wirausaha dan untuk mempertahankan organisasi, LEMIGAS memiliki sertifikat organisasi nasional dan internasional seperti ISO 9001: 2008, Standar Nasional Indonesia (SNI), ISO / IEC 17025: 2008, ISO 14001: 2004, dan OHSAS 18001: 2007, dan keseimbangan kartu skor berkaitan dengan jaminan kualitas kegiatan $\mathrm{R}$ \& $\mathrm{D}$, layanan untuk pengujian minyak dan gas dan teknologinya, dan profesionalisme, organisasi yang efisien dan efektif. Dalam pengelolaan keuangan, LEMIGAS didukung oleh UU Menteri ESDM terkait pengelolaan keuangan internal yang tidak diatur oleh hukum keuangan Kementerian Keuangan. Sebagai 
pemerintahan wirausaha, LEMIGAS diawasi oleh unit pengawasan keuangan internal dan komisi untuk mengawasi keuangan.

Dalam kegiatan litbang, BLU LEMIGAS berwenang dan mampu melakukan penelitian teknologi minyak dan gas dari hulu ke hilir di Indonesia. Lembaga ini memiliki peralatan uji laboratorium yang paling lengkap di Indonesia. Semua litbang dan peralatan laboratorium pengujian telah diakreditasi oleh Komite Akreditasi Nasional (KAN). Banyak publikasi ilmiah nasional dan internasional diterbitkan oleh BLU LEMIGAS dengan menggunakan sistem off line dan on line (sistem jurnal online), bahkan sudah menjadi OJS (Open Journal System). Hingga 2016, BLU LEMIGAS telah mendaftarkan 36 paten kepada Direktorat Jenderal Hak Kekayaan Intelektual (Dirjen-HAKI) di Kementerian Hukum dan Hak Asasi Manusia (Kementerian-Hukum-dan-HAM). Dari unit-unit tersebut, 22 unit telah terdaftar, 3 unit dalam proses publikasi, 3 unit dalam substantif crosscheck, dan 8 unit dalam tahap pengisian tanggal di Dirjen-HAKI.

Dalam menyediakan layanan pengujian teknologi minyak dan gas bumi, BLU LEMIGAS melampirkan banyak dokumen seperti, hasil teknis pengujian laboratorium, analisis pengujian laboratorium, sertifikat terpercaya dan legal, dan rekomendasi hasil pengujian laboratorium. Ini terlihat berbeda dari unit laboratorium pengujian minyak dan gas bumi swasta lainnya. Sebagai hasilnya, BLU LEMIGAS memiliki pabrik LOBP pada minyakblending (pabrik pelumas) yang hanya digunakan di internal Kementerian ESDM. BLU LEMIGAS juga telah dinominasikan sebagai salah satu Pusat Sainsdan-Teknologi Luar Biasa yang dianugerahkan oleh Kementerian Reserch, Teknologi, dan Pendidikan Tinggi (Kemenristekdikti) pada tahun 2015.

Untuk memperkuat produktivitas, ada sejumlah sumber daya manusia pendukung yang sepenuhnya dicatat oleh 740 orang pada bulan Desember 2016, terdiri dari 487 pegawai negeri dan 253 pegawai profesional/ non-sipil. Hal ini disusun sebagai pendidikan sebagai berikut: 4 orang di tingkat doktor, 112 orang di gelar master, 137 orang di sarjana, 30 orang dalam diploma, dan 134 orang di bawah SMA.

\section{Tantangan BLU LEMIGAS}

Dalam melakukan kewirausahaan pemerintah, BLU LEMIGAS menghadapi tantangan yang dapat mempengaruhi kinerja dan produktivitas organisasi.
Salah satu contohnya adalah munculnya dualisme untuk kinerja LEMIGAS sebagai BLU dan LEMIGAS sebagai center of excellent (pusat litbang migas pemerintah). Pada satu sisi, LEMIGAS berstatus abdi negara/ pegawai negeri yang menginduk pada lewel diatasnya. Hal tersebut secara hirarki maka LEMIGAS harus mengikuti aturan organisasi Kementerian ESDM. Namun sebagai BLU, LEMIGAS harus mengikuti aturan Kementerian Keuangan terkait pengelolaan keuangan. Hal tersebut seringkali menjadi ambiguitas dalam pengambilan keputusan untuk memperluas layanan publik. Perlu diketahui bahwa aktivitas kewirausahaan (BLU LEMIGAS) tidak untuk mencari keuntungan semata, melainkan bertujuan untuk meningkatkan produktivitas secara efisien dan efektif.

Peraturan pemerintah Nomor 23 Tahun 2005 tentang BLU sering membatasi LEMIGAS untuk menjaring pelanggan yang lebih luas di pasar, sulit bersaing dengan perusahaan swasta di bidang yang sama misalnya dalam persaingan tarif layanan antar kontestan dan status lembaga publik yang disandang LEMIGAS dalam berkompetisi. Status ambiguitas lembaga publik sedikit banyak telah mengakibatkan motivasi pekerja semakin berkurang, dan sedikit pekerja terampil berpindah ke unit atau direktorat lain di Kementerian ESDM.

Tantangan lain adalah pendapatan BLU hanya berasal dari layanan jasa teknologi (APBN - PNBP), bukan dari kegiatan litbang (APBN - RM). Ini terlihat dari besarnya pembiyaan pemeliharaan paten yang terus berjalan dari tahun ke tahun tidak sebanding dengan royalti paten yang sangat minim. Beberapa paten telah digunakan oleh pelanggan, tetapi tidak dapat dijual bebas ke pasar karena peraturan pemerintah yang rijit. Secara praktis, hasil litbang tidak dikomersialkan secara optimal karena sifat dasar penelitian yang setiap hasil penelitian membutuhkan keterlibatan jaringan aktor dan faktor sosial ekonomi (bukan teknologi semata) dalam jangka waktu lama untuk diterapkan pada level end user (Wu et al. 2015).

\section{KESIMPULAN}

Pemerintahan wirausaha atau BLU adalah tipe baru organisasi publik untuk mengelola keuangan organisasi. Perubahan manajemen diperlukan untuk menyesuaikan antara kepentingan organisasi, pelanggan, dan hukum pemerintah. Salah satu organisasi publik yang menerapkan BLU adalah 
LEMIGAS. Lembaga ini memiliki banyak kekuatan untuk mempertahankan dan bersaing dengan pesaing lain dalam memberikan layanan minyak dan gas bumi. Meskipun demikian, tantangan dihadapi oleh LEMIGAS seperti kekakuan hukum pemerintah skema keuangan, hasil penelitian non-komersial, status ambiguitas organisasi.

Di masa depan, LEMIGAS harus memfokuskan kembali strukturnya dan memisahkan antara layanan jasa teknologi minyak dan gas bumi dengan kegiatan litbang minyak dan gas bumi. Hal ini bertujuan untuk memudahkan manajemen keuangan agar dapat bersaing dengan organisasi lain dalam memberikan layanan minyak dan gas bumi khususnya tarif layanan yang sesuai pasaran tetapi layanan lebih baik dari yang lain (cheaper, better, faster). Oleh karena itu, peran kepemimpinan internal yang kuat adalah suatu keharusan untuk menjalin hubungan baik pada struktur yang lebih tinggi dan untuk memperluas jejaring mitra bisnis (konsumen/ pelanggan di industri migas).

\section{DAFTAR PUSTAKA}

de Ferranti, David; Jacinto, Justin; Ody, Anthony J. and Ramshaw, Graeme, 2009, How to Improve Governance: A New Framework for Analysis and Action, Washington, D.C.: Brookings Institution Press.

Finlay, Susanna and Sandall, Jane, 2009, "Someone's Rooting for You': Continuity,
Advocacy and Street-Level Bureaucracy in UK Maternal Healthcare, Social Science \& Medicine, 69, 1228-1235.

Jasiulewicz-Kaczmarek, Małgorzata, 2016, SWOT Analysis for Planned Maintenance Strategy - A Case Study, IFAC-Papers OnLine 49-12, 674 679.

Leathard, Audrey, 2005, Evaluating Interagency Working in Health and Social Care: Politics, Policies and Outcomes for Service Users, In David Taylor and Susan Balloch (Eds), The Politics of Evaluation: Participation and Policy Implementation (pp. 135-151), Bristol: The Policy Press University of Bristol.

LEMIGAS, 2017, LAKIP 2016. Jakarta. LEMIGAS.

LEMIGAS, 2018, Rencana Strategis. Jakarta. LEMIGAS.

Shafritz, Jay M; Russell, E.W.; Borick, Christopher P., 2013, Introducing Public Administration: Eighth Edition, London: Pearson.

Stewart, Jenny, 2009, Public Policy Values, London: Palgrave Macmillan.

Wu, Yonghong; Welch, Eric W.; Huang, Wan-Ling, 2015, Commercialization of University Inventions: Individual and Institutional Factors Affecting Licensing of University Patents, Technovation, 36-37, 12-25.

Zahariadis, Nikolaos, 2007, The Multiple Streams Framework Structure, Limitations, Prospects. In Paul A. Sabatite (Ed), Theories of the Policy Process (pp.65-92), Colorado: Westview Press. 